\title{
The Account of the Fukushima Daiichi Accident by the Plant Manager: A Source to Study Engineering Thinking in Extreme Situations
}

\begin{abstract}
Aissame Afrouss
Abstract The concept of "engineering thinking in extreme situations" has been defined to make up for an epistemological lack in the field of Safety Studies. After the accident at the Fukushima Daiichi plant, official reports did not take an interest in analysing the conditions in which the recovery efforts had to be carried out. The description of the accident and its representation in the accident investigation reports convey these shortcomings. The Fukushima Daiichi plant manager Masao Yoshida testimony may allow us address them partly. Actually, the transcription of his hearings contains essential details and information to understand the sequence of events which took place after the 2011 Tōhoku earthquake and tsunami. This article intends to show the importance of studying this narrative, in order to highlight the relations between the Fukushima accident management and the concept of "engineering thinking in extreme situations".
\end{abstract}

Keywords Engineering thinking - Extreme situation - Yoshida testimony • Narrative analysis - Mental representation

\section{Introduction}

The Fukushima Daiichi accident is regarded as one of History's most important nuclear accidents, along with those at Chernobyl and Three Miles Island. Yet, the institutional accident investigation reports do not allow us to comprehend fully the complexity of the accident management by the operators. To address this problem, the concept of "engineering thinking in extreme situations" has been defined as "engineering activities that are significantly impeded due to the lack of resources in the face of a societal emergency" [1].

\footnotetext{
A. Afrouss $(\square)$

Centre for Research on Risks and Crises (CRC), MINES ParisTech/PSL-Research University, Sophia Antipolis, France

e-mail: aissame.afrouss@mines-paristech.fr

(C) The Author(s) 2017

J. Ahn et al. (eds.), Resilience: A New Paradigm of Nuclear Safety,

DOI 10.1007/978-3-319-58768-4_19
} 
Masao Yoshida, the plant manager, has been heard by the Investigation Committee on the Accident at the Fukushima Nuclear Power Stations (ICANPS) on the plant's management after the earthquake and the actions undertook to deal with the accident. His account, made public in September 2014, is currently being edited in French [2]. ${ }^{1}$ The testimony enables us not only to address the silence of the reports, but to learn more about the factors affecting the decision-making and the action-taking during "extreme situations" as well. During such a situation, the actions taken by workers do not enable them to regain control of their production tool, and are regarded as responsible of an impending and irreversible damage [3].

This article therefore intends to demonstrate the importance of the Masao Yoshida first-hand account, and how its study contributes to the concept of "engineering thinking in extreme situations". In the first part of the article, some accident investigation reports and there content are presented. In the second part, correlations between the hearings of Yoshida and the narrative form are highlighted, and then, the significance of the manager's disclosures for "engineering thinking in extreme situations" is revealed.

\section{The Accident Investigation Reports}

The first part presents the four institutional reports used in this study and the bodies that produced them. Then, it sums their content up, with an eye to analyse the representation they make of the accident.

\subsection{Description of the Institutional Report}

Following the Fukushima accident, several bodies published reports about its causes. These reports also point out the lessons that are to be learned to enhance nuclear facilities safety. This paper discusses the reports issued by the Investigation Committee on the Accident at the Fukushima Nuclear Power Stations [4-7]. These documents have been written by two Japanese, an international and an American organisation. Obviously, they were drafted with different purposes and present different feedbacks and recommendations.

The Cabinet of Japan has decided to create The Investigation Committee on the Accident at the Fukushima Nuclear Power Stations (ICANPS) on 24 may 2011. The ten members (researchers, jurists...) are put under the direction of Yotaro Hatamura, professor emeritus of the University of Tokyo. The aim of the Committee is to

\footnotetext{
${ }^{1}$ The CRC - MINES ParisTech is publishing a French version of the entirety of the hearings of Yoshida. The first volume which contains the auditions of 22 and 29 July 2011 is available since March 2015. The auditions of 8 and 9 august are gathered in the second volume which was published in March 2016. The following hearings are to be found in the third volume.
} 
suggest recommendations to limit the expansion of the damages of the accident and to prevent the recurrence of similar crises. The investigation should identify the causes of the accident and the causes of the damages it inflicted to Japan. The members of the Committee ambitioned to carry out a thorough investigation which outcome would satisfy every question about the accident, and whose results would remain valid for the next century. The final report is issued in July 2012.

The National Diet of Japan Fukushima Nuclear Accident Independent Investigation Commission (NAIIC) has been established via a dedicated actnamed NAIIC act - on 30 October 2011. On 8 December 2011, the ten members of the Commission are designated by the Diet president. Kiyoshi Kurokawa, a doctor of medicine and former chairperson of the Science Council of Japan is appointed chairperson. The nine other members are scientists, legal experts and politicians. The investigation of the NAIIC focuses on the causes of the accident and of the damage of the accident. It also reminds how the stakeholders dealt with the accident, and points out the lack of efficiency of their responses in the face of the extreme situation. Finally, it suggests measures to be applied in order to prevent another nuclear accident from happening in Japan and to mitigate its possible consequences. The final report is published in September 2012.

One of The Nuclear Energy Agency's (NEA) tasks is to strengthen the legal, scientific and technological bases of the nuclear safety in the Organisation for Economic Co-operation and Development (OECD). In September 2013, it drew up a report on the lessons learnt from the Fukushima accident. This document has been written under the direction of the Director-General Luis Echávarri. It lists the efforts made by the OECD member countries to improve safety management following the accident, and gives general recommendations based on the main lessons learned.

The American National Academy of Science published a report sponsored by the United States Nuclear Regulatory Commission in July 2014. The study has been carried out by a committee consisting of various scientists and engineers with different competencies. The committee was led by Norman P. Neureiter. The aim of the report is to summarize the multiple causes of the nuclear accident and to suggest recommendations to enhance the American nuclear facilities' safety.

\subsection{The Accident According to the Reports}

The analysis of the recommendations given in the different reports highlights the flaws identified by the institutional bodies. This helps to understand their representation of the accident and the crisis management. In this article, the notion of "representation" refers to a mental map, that being the whole of causal, proximal and influence relations established by people in order to understand a problem or a problematic issue [8]. 
According to the four reports, the Fukushima Daiichi accident is due to a lack of preparation of TEPCO and the concerned institutions to deal with such an event. They reveal therefore that TEPCO staff lacked adequate training and appropriate skills to respond to emergency situations. They also point out the fact the communication between the workers and the authorities and the poor coordination of the emergency response centres has not permitted to react effectively.

Furthermore, the accident could have been avoided if the state of the art and the new safety concepts have been applied, especially the defence-in-depth concept. TEPCO and the Japanese institutions had not taken the appropriate measures to bring their facilities' safety up to current international standards. The reports underline also the necessity for all nuclear power plants to strengthen the defence-in-depth provisions, and to consider the occurrence of beyond design basis and multi-unit accidents.

Another recommendation involves the lack of independence of the Nuclear and Industrial Safety Agency (NISA). Although the nuclear regulatory body knew about some of TEPCO safety deficiencies, it did not face its responsibilities. The competencies, the involvement and the transparency of the NISA have been called into question. Consequently, Japan needed to deeply reform its nuclear facilities' regulation and monitoring system.

This short overview shows that the four reports do not bring renewed reflections on accident management. Instead, they only emphasise the need to strengthen concepts already acknowledged and to take larger margins to avoid potential accidents. New standards might be suggested and taking beyond design basis accidents is encouraged. To sum up, major accident management is regarded through the already existing organisation and resources.

However, during the accident, the operators found themselves in the face of a scenario that exceeds by far every known standard. The loss of electricity resources and the worsening of the site conditions point out the need to adapt to new and unexpected circumstances. The hearings of Masao Yoshida bring out a new consideration of the accident, giving specifications and details unfound elsewhere. His testimony enables a better understanding of the proceedings of the Fukushima crisis management.

\section{The Importance of Yoshida's Testimony}

This section analyses the hearings of Masao Yoshida and shows that the testimony he made can be considered as a narrative. A comparison is then made between the content of the institutional reports and the disclosures of the manager, binding these information and the concept of "engineering thinking in extreme situations". 


\subsection{The Yoshida Testimony: A Narrative of the Accident}

The hearings of Masao Yoshida have been carried out by ICANPS. The Committee interrogated several political and technical actors, who were involved during the accident management. The manager has been summoned five times by the Commissions, between 22 July and 22 November 2011. These interviews lasted $28 \mathrm{~h}$ in total and primarily addressed the actions that were carried out in response to the accident. The transcript of the hearing was made public by the Japanese government on 11 September 2014 in the form of eleven documents. ${ }^{2}$

The content of these hearings can be regarded as a narrative of the nuclear accident. A narrative corresponds to an oral, written, drawn or ritualised representation of real or fiction events, arranged according to a chronological organisation and forming a consistent whole [9]. A life history is defined as "a generic expression where one person tells their life or a part of their life to one or more interlocutors. This narrative may lead to a book, a recording or a film" (Legrand, cited in Burrick [10]).

Yoshida's life history is produced during a "semi-structured interview". This kind of interview is an "interaction close to conversation, thanks to the continuous adaptation of interrogations and interventions of the researcher to the ongoing exchange" [11]. In such a narrative, the person interviewed-Yoshida-leads his discourse according to what he considers the investigator's expectations are [12]. The semi-structured interviews also encourage the narrator to digress and tell anecdotes [13].

These deviations from the main narrative plot are useful to add meaning to the story, by providing explanations and/or comparisons. In his account, via the addition of details and information, the narrator intends justifying the sequence of events: this guarantees the overall outline and the intelligibility of the narration. Yoshida selects the events he believes significant and establishes "specific connexions to provide consistency" [14].

Yoshida's account is obviously based on his own memories. The facts are then arranged according to the-necessarily subjective-point of view of a major stakeholder of the accident management. Even though the main plot of the account is led by the investigators, the overall meaning is instilled by the interviewee. The manager resorts to his own representational system to build a consistency between the facts reported.

The metaphors used and the reference to his states of mind reveals the complexity and the extent of the troubles that had to be dealt with during the decision-making. It is interesting to note the deviations to the main plot since they enable us to reveal the "absences" in the official investigation reports.

\footnotetext{
${ }^{2}$ These documents are available in Japanese in the following address: http://www.cas.go.jp/jp/ genpatsujiko/hearing_koukai/hearing_list.html.
} 


\subsection{The Disclosures of the Manager}

The analysis of the manager's testimony shows correlations between the accident management and the concept of "engineering thinking in extreme situations". Some of the information it contains is new, and can be divided into three aspects: factual, representational and operational.

The institutional reports present the succession of events in the Fukushima Daiichi plant with an a posteriori posture. They reflect a desire of comprehensiveness and explanation of all phenomena, notably from a technical point of view. This approach makes the reports relate some of the facts as they were deduced by simulation, especially when they concern chronological indications, as they were established by TEPCO. Yet, the Fukushima Daiichi onsite emergency response centre ignored about many of these phenomena until the simulations were performed. Indeed, certain phenomena were presumed to have happened only after the event, for example that a high concentration of hydrogen was the reason for the explosion of the first reactor building. Furthermore, Yoshida tells the investigators many times that he cannot recall some details or that he did not know about facts stated during the interview. This point is important, in particular to understand the uncertainty that reigned at the Fukushima site after the tsunami hit. It means that decisions must have been taken in the absence of knowledge about certain reactor parameters. Furthermore, the emergency response centre had to coordinate multiple tasks simultaneously, which cannot be effectively represented by a classic schema where events follow each other in chronological succession. The decisions and the actions that were taken, with a notable lack of resources, depended on one another. Many important factors came into play, including slow progress in completing tasks, the impact of events on the viability of the site, lessons learned from interventions at other plants, and the mobilization of resources for other activities.

From a representational point of view, some of the reports describe the Fukushima Daiichi reactors one by one. As for the manager's account, it reveals that the emergency response centre had to deal with the whole site at the same time, in order to avoid the deterioration of the different facilities. In addition, the evolution of the emotional state of Yoshida shows extreme complications in the handling of the situation. This can be proven by an excerpt of the hearings. After the earthquake, the concerned employees gathered in the anti-seismic building and established an informal emergency response centre. Since the tsunami warnings, this group considered the probability of an anomaly in the reactors' cooling. However it is the loss of the electric power resources following the tsunami that causes the distress of the group ${ }^{3}$ : "We're so dismayed that we're speechless. For the time being, we're quiet

\footnotetext{
${ }^{3}$ The plant manager has to warn the authorities in case of an emergency situation, such as the loss of power resources. He then constitutes an emergency response center under his direction; in accordance with the article 10 of the Japanese act No. 156 on the Special Measures Concerning Nuclear Emergency Preparedness.
} 
and we're tackling administrative tasks, as the declaration of loss of all AC power, the much talked about article 10. However, as I told you a bit earlier, as we carry out these administrative tasks, emotionally, we're devastated". The team finds itself, from this moment on, "in the face of a catastrophe" [2].

Devastation, nervousness, frustration and fear relate to an emotional anxiety which comes into play in the decision making and the action taking in an accident situation. The third aspect of the information found in the account of Yoshida is complementary to the others. It relates to the actions undertaken in the field. The manager underlines many times the complexity faced to see the tasks through to the end. This inability to have an effect on their work tool, paired up with the lack of understanding and the impatience of the off-site executives, contributes to the extreme situation experienced by the workers [2]. The attempts to vent the reactor 2 , mentioned in few institutional reports, illustrate perfectly the gap between the field and the executives. TEPCO headquarters repeatedly issued orders to proceed with venting; although teams worked through the night, no workable solution could be found due to lack of suitable resources. Yoshida states his annoyance with this lack of understanding, which was perceived by the emergency response centre as a failure to acknowledge the work they were doing, and their ongoing efforts. This only served to increase the frustration of teams who could not make the unit respond to their actions. These strong emotions and the role they play in decision making must be taken into account, if we are to have a better understanding of how the accident was managed.

The analysis of the hearings permits to better take some factors inherent to the "extreme situation" concept into account. For instance, the uncertainty of the situation, the lack and inappropriateness of the available resources to deal with the accident, the social and hierarchy pressure, and the powerlessness facing the progressive decay of the facilities can be mentioned.

The factual lacks and the arrangement of facts in the reports do not convey accurately the complexity and the stakes of the crisis as faced by the workers and the onsite emergency response centre. Nevertheless, it should be made clear that the testimony is a reflection of how the manager recalls the story and depends particularly on his memory and the representation he makes of the whole situation. Thus, the account does not correspond to the objective succession of events, as they took place in the Fukushima Daiichi plant following the arrival of the tsunami.

\section{Conclusion}

The account of the accident by Yoshida is a valuable material to understand the Fukushima Daiichi accident management. The testimony makes up for some factual shortcomings and clarifies some information given by the institutional reports. 
The information and the disclosures available in the narrative allow to establish a link between the Fukushima accident management and the concept of "engineering thinking in extreme situations". A more thorough analysis of this document should consequently showcase some pointers of this kind of engineering activities, performed in very hostile conditions with limited resources to mobilise. The analysis of some excerpts could for example show the influence of social pressureembodied in the repeated demands of the Japanese Government —on the operations undertook to preserve the reactors' integrity.

The narrativisation of the nuclear catastrophe by Yoshida is also interesting to study. This research perspective should underline, for instance, how the manager relates the relation he maintained with the network of stakeholders in the accident's management, and the evolution of their interactions under the threat of physical, psychological and social destruction.

\section{References}

1. F. Guarnieri, S. Travadel, Engineering thinking in emergency situations: a new nuclear safety concept. Bulletin of Atomic Scientists 70(6), 79-86 (2014)

2. F. Guarnieri (ed.), L'accident de Fukushima Daiichi: le récit du directeur de la centrale, vol. 1 (Presses des Mines, Paris, L'anéantissement, 2015)

3. S. Travadel, F. Guarnieri, «L'agir en situation extrême», L'accident de Fukushima Daiichi: le récit du directeur de la centrale, volume 1, L'anéantissement, ed. by F. Guarnieri (Presses des Mines, Paris, 2015)

4. Investigation Committee on the Accident at the Fukushima Nuclear Power Stations of Tokyo Electric Power Company. Final Report (2012)

5. The National Diet of Japan, The Fukushima Nuclear Accident Independent Investigation Commission (2012)

6. Nuclear Energy Agency, The Fukushima-Daiichi Nuclear Power Plant AccidentOECD/NEA Nuclear Safety, Response and Lessons learnt, NEA No. 7161 (2013)

7. The National Academy of Science, Lessons Learned from the Fukushima Nuclear Accident for Improving Safety of U.S. Nuclear Plants (The National Academies Press, Washington, DC, 2014)

8. S. Chaxel, C. Fiorelli, P. Moity-Maïzi, «Les récits de vie: outils pour la compréhension et catalyseurs pour l'action». ¿Interrogations? Revue pluridisciplinaire de sciences humaines et sociales 17 (2014)

9. J.M. Adam, Le récit, P.U.F. «Que sais-je?» (Paris, 1996)

10. D. Burrick, «Une épistémologie du récit de vie» Recherches Qualitatives. Hors-Série 8, 7-36 (2010)

11. S. Nossik, «Les récits de vie comme corpus sociolinguistique: une approche discursive et interactionnelle». Corpus, 10, 119-135 (2011)

12. P. Brun, «Le récit de vie dans les sciences sociales». Quart Monde (2004)

13. M.C. Bernard, «La "présentation de soi": cadre pour aborder l'analyse de récits de vie.» ¿Interrogations? Revue pluridisciplinaire de sciences humaines et sociales 17 (2014)

14. P. Bourdieu, L'illusion biographique. Actes de la recherche en sciences sociales 62-63, 69-72 (1986) 
Open Access This chapter is licensed under the terms of the Creative Commons Attribution 4.0 International License (http://creativecommons.org/licenses/by/4.0/), which permits use, sharing, adaptation, distribution and reproduction in any medium or format, as long as you give appropriate credit to the original author(s) and the source, provide a link to the Creative Commons license and indicate if changes were made.

The images or other third party material in this chapter are included in the chapter's Creative Commons license, unless indicated otherwise in a credit line to the material. If material is not included in the chapter's Creative Commons license and your intended use is not permitted by statutory regulation or exceeds the permitted use, you will need to obtain permission directly from the copyright holder. 